\title{
Pregnancy-associated breast cancer as a screening and diagnostic challenge
}

\author{
Barbara Radecka1,2 \\ 'Institute of Medical Sciences, Faculty of Medicine, University of Opole, Opole, Poland \\ ${ }^{2}$ Clinical Oncology Department with an Outpatient Unit, Tadeusz Koszarowski Oncology Centre in Opole, Opole, Poland
}

Pregnancy-associated cancer (diagnosed during pregnancy or up to a year after), also known as gestational cancer, is a rare situation with an estimated incidence of 1 case in every 1000 pregnancies and accounting for approximately $0.1 \%$ of all malignant tumors.

The most common type of pregnancy-associated cancer is breast cancer, which comprises $50 \%$ of all cancers during pregnancy. There is also cervical cancer, malignant melanoma, lymphomas (Hodgkin's and non-Hodgkin's) and leukemias, ovarian cancer, and colorectal cancer diagnosed [1]. These histological types of malignancies are also among the most frequent cancer sites in non-pregnant women at younger ages.

It is estimated that 1 in 3,000 to 10,000 pregnant women will develop breast cancer. The number of women diagnosed with cancer while pregnant is expected to increase because more women are delaying childbirth into their thirties; the risk of developing most cancers increases with age. The age of pregnant women with breast cancer ranges from 32 to 38 years (median 34 years). The risk of breast cancer varies throughout a woman's life. In patients with a genetic predisposition, it is higher in the reproductive period; BRCA1 mutations are associated with a 3.8\% annual risk between the ages of 25 and $40[2,3]$. There is a lack of solid literature-based evidence pertaining to high-risk cancer screening in pregnant and lactating women, although this issue becomes increasingly clinically relevant because women are delaying childbearing [3]. The authors of the literature review indicate that the opinions of experts dominate among the reports on this issue, which explains the lack of standardized guidelines for high-risk breast cancer screening in this population [3]. Physical breast examination screenings during pregnancy and breastfeeding is strongly recommended, while mammography (MMG), magnetic resonance imaging (MRI) and ultrasound imaging (USG) is not considered appropriate for screening in this population [3].

Diagnosing and treating pregnant women is particularly difficult because it affects both the pregnant woman and the fetus. No randomized, controlled trials for this issue are available and most of the data guiding diagnosis and treatment come from case reports, small case series, or retrospective cohort analysis [10].

Pregnancy-associated breast cancer (PABC) is usually diagnosed at a more advanced stage than in the non-pregnant population. A growing mass in the breast can be treated as a physiological response of glandular tissue to hormonal changes related to pregnancy like increased glandularity and density of the breast tissue. Diagnostics in pregnant women is delayed by 2-7 months after the first symptoms appear. Delay in the diagnosis of PABC remains an important concern regarding the impact on prognosis because it affects the increase in the number of patients with metastases to the regional lymph nodes [4]. Most patients present with a lump detected through breast self-examination [5]. A gynecologist should perform a physical examination of the breast on every

\section{How to cite:}

Radecka B. Pregnancy-associated breast cancer as a screening and diagnostic challenge. NOWOTWORY J Oncol 2021; 71: 316-318. 
pregnant woman. A new palpable mass that does not resolve within 2 weeks should be investigated further, although it is reported that approximately $80 \%$ of such breast biopsies are benign $[6,7,10]$. The risk of development of a milk-fistula after such a biopsy is low.

USG is the preferred imaging modality because it does not carry a risk for fetal radiation exposure. It is very useful in distinguishing cystic and solid tumors, and sensitive (93-100\% sensitivity) methods in pregnant and lactating women and for detecting axillary metastases [8]. Ultrasound examination should include both breasts (not only suspected) and regional lymph nodes [4]. In approximately $90 \%$ of women, USG imaging confirms clinical suspicion of breast cancer.

MMG with abdominal shielding can be performed with minimal risk to the fetus (radiation exposure is estimated ad 0.4 cGy) [9]. But reported sensitivity of MMG for detecting breast cancers in a pregnant breast is low, with ranges from $63 \%$ to $78 \%$ [10]. Due to increased water content in the pregnant breast and loss of contrasting fat, the interpretation of mammography is difficult [10]. Therefore, this imaging method is not recommended during pregnancy [10].

There are no obvious contraindications to the use of MRI even in the first trimester of pregnancy, but MRI of both the breasts and other regions of the body in pregnant women is not routinely recommended and there is currently no consensus on this matter. In special cases (e.g., suspected central nervous system metastases) it can be ordered. The experience with MRI from the second trimester of pregnancy, including the administration of gadolinium, indicates the risk of toxic effects on the fetus because gadolinium can cross the placenta [11]. Nevertheless, the use of gadolinium-based and iodinated contrast agents during pregnancy and lactation has not been well studied in human subjects [12].

All staging investigations that are likely to cause any risk to the fetus should be undertaken only if the benefits outweigh the risks [13]. A chest radiography (X-ray) with adequate shielding is considered safe in pregnant women and should be performed when necessary [4]. Positron emission computed tomography (PET-CT), computed tomography (CT), and pelvic radiography involves more radiation than $\mathrm{MRI}$, and hence are not the preferred imaging modalities [13]. Bone scans, although rarely used, result in only 0.00194 Gy of radiation exposure to the fetus [13].

Considering the young age of patients with breast cancer during pregnancy, proper genetic counseling should be offered [14].

In any case where breast cancer is suspected, a histopathological diagnosis should be performed. A USG guided core-needle biopsy is recommended and in the case of suspicious lymph nodes, a fine needle biopsy should be performed. The histopathological examination confirms diagnosis and assesses the prognostic and predictive factors: expression of estrogen receptors (ER) and progesterone receptors (PgR), expression of the human epidermal growth factor receptor 2 (HER2), Ki-67. It is important to inform the pathologist that the biopsy is being performed on a pregnant woman [4]

Doctors should be mindful of the possibility of breast cancer in pregnant women, present oncological vigilance, and, in the case of abnormalities, conduct immediate diagnostics. There are reports highlighting the importance of proper breast oncology surveillance during pregnancy [15]. The management of pregnant women with diagnosed breast cancer requires an experienced and multidisciplinary medical team working closely with each other. The team must assess the benefits of the ongoing oncological treatment and the risks associated with the therapy for the fetus. The prognosis of pregnant women with proper treatment is comparable to that of women with the disease at the same stage of disease, but not pregnant. This fact should be clearly stated to the patient during the first consultation. Delivery should be performed on time and iatrogenic prematurity should be avoided [16].

\section{Conflict of interest: none declared}

\author{
Barbara Radecka \\ University of Opole \\ Faculty of Medicine \\ Institute of Medical Sciences \\ ul. Oleska 48 \\ 45-052 Opole, Poland \\ e-mail: barbara.s.radecka@gmail.com
}

Received: 16 May 2021

Accepted: 1 Jun 2021

\section{References}

1. Pavlidis N. Coexistence of Pregnancy and Malignancy. The Oncologist. 2002; 7(6): 573-573, doi: 10.1634/theoncologist.7-6-573.

2. Brose MS, RebbeckTR, Calzone KA, et al. Cancer risk estimates for BRCA1 mutation carriers identified in a risk evaluation program. J Natl Cancer Inst. 2002; 94(18): 1365-1372, doi: 10.1093/jnci/94.18.1365, indexed in Pubmed: 12237282.

3. Zha N, Alabousi $\mathrm{M}$, Abdullah $\mathrm{P}$, et al. Breast Cancer Screening in High-Risk Patients during Pregnancy and Breastfeeding: A Systematic Review of the Literature. Journal of Breast Imaging. 2019; 1(2): 92-98, doi: 10.1093/jbi/wby015.

4. Kakoulidis I, Skagias L, Politi E. Pregnancy associated breast cancer (PABC): aspects in diagnosis. Breast Dis. 2015; 35(3): 157-166, doi: 10.3233/BD-150408, indexed in Pubmed: 26406540.

5. Córdoba O, Llurba E, Saura C, et al. Multidisciplinary approach to breast cancer diagnosed during pregnancy: maternal and neonatal outcomes. Breast. 2013;22(4):515-519, doi: 10.1016/j.breast.2012.10.005, indexed in Pubmed: 23116970.

6. Loibl S, Minckwitz Gv, Gwyn K, et al. Breast carcinoma during pregnancy Cancer. 2006; 106(2): 237-246, doi: 10.1002/cncr.21610.

7. Collins J, Liao S, Wile A. Surgical management of breast masses associated with pregnancy and lactation. J Reprod Med. 1995; 40(11): 785-788.

8. Ahn BoY, Kim HH, Moon WK, et al. Pregnancy- and lactation-associated breast cancer: mammographic and sonographic findings. J Ultrasound Med. 2003; 22(5): 491-7; quiz 498, doi: 10.7863/jum.2003.22.5.491, indexed in Pubmed: 12751860.

9. Nicklas $\mathrm{AH}$, Baker ME. Imaging strategies in the pregnant cancer patient Semin Oncol. 2000; 27(6): 623-632, indexed in Pubmed: 11130469.

10. Litton JK, Theriault RL, Gonzalez-Angulo AM. Breast cancer diagnosis during pregnancy. Womens Health (Lond). 2009; 5(3): 243-249, doi: 10.2217/whe.09.2, indexed in Pubmed: 19392610 
11. Webb JAW, Thomsen HS, Morcos SK, et al. Members of Contrast Media Safety Committee of European Society of Urogenital Radiology (ESUR). The use of iodinated and gadolinium contrast media during pregnancy and lactation. Eur Radiol. 2005; 15(6): 1234-1240, doi: 10.1007/s00330004-2583-y, indexed in Pubmed: 15609057.

12. Wang PI, Chong ST, Kielar AZ, et al. Imaging of pregnant and lactating patients: part 1, evidence-based review and recommendations. AJR Am J Roentgenol. 2012; 198(4): 778-784, doi: 10.2214/AJR.11.7405, indexed in Pubmed: 22451541.

13. Durrani S, Akbar S, Heena H. Breast Cancer During Pregnancy. Cureus. 2018; 10(7): e2941, doi: 10.7759/cureus.2941, indexed in Pubmed: 30202672 .
14. Paluch-Shimon $S$, Cardoso F Partridge $\mathrm{AH}$, et al ESO-ESMO 4th International Consensus Guidelines for Breast Cancer in Young Women (BCY4). Ann Oncol. 2020; 31(6): 674-696, doi: 10.1016/j.annonc.2020.03.284, indexed in Pubmed: 32199930.

15. Kalantarova A, Zembol NJ, Kufel-Grabowska J. Pregnancy-associated breast cancer as a screening and diagnostic challenge: a case report. NOWOTWORY J Oncol. 2021; 71(3): 162-164, doi: 10.5603/NJO. a2021.0017.

16. Jeziorski A, Nowecki Zl. Chirurgiczne leczenie zmian nowotworowych piersi - Konsensus Polskiego Towarzystwa Chirurgii Onkologicznej pod patronatem merytorycznym Konsultanta Krajowego w dziedzinie Chirurgii Onkologicznej. Via Medica, Gdańsk 2016. 